ORIGINAL ARTICLE

\title{
Mortality of workers at a nickel carbonyl refinery, 1958-2000
}

\section{T Sorahan, S P Williams}

See end of article for authors' affiliations

.....................

Correspondence to: Prof. T Sorahan, Institute of Occupational and Environmental Medicine, University of Birmingham, Edgbaston, Birmingham B15 2T, UK; T.M. Sorahan@bham.ac.uk

Accepted

5 September 2004
Background: Excess risks of respiratory cancer have been shown in some groups of nickel exposed workers. It is clear, however, that not all forms of nickel exposure are implicated in these excess risks. Aim: To determine whether occupational exposures received in a modern nickel carbonyl refinery lead to increased risks of cancer, in particular nasal cancer and lung cancer.

Methods: The mortality experienced by a cohort of 812 workers employed at a nickel refinery was investigated. Study subjects were all male workforce employees first employed in the period 1953-92 who had at least five years' employment with the company. Observed numbers of cause specific deaths were compared with expectations based on national mortality rates; SMRs were also calculated by period from commencing employment, year of commencing employment, and type of work.

Results: Overall, standardised mortality ratios (SMRs) were close to 100 for all causes (Obs 191, SMR 96, $95 \% \mathrm{Cl} 83$ to 111 ), all neoplasms (Obs 63, SMR 104, 95\% Cl 80 to 133), non-malignant diseases of the respiratory system (Obs 18, SMR 97, 95\% Cl 57 to 153), and diseases of the circulatory system (Obs 85, SMR 94, 95\% Cl 75 to 116). There were no significantly increased SMRs for any site of cancer. There was a non-significant excess for lung cancer (Obs 28, Exp 20.17, SMR 139,95\% Cl 92 to 201), and in subgroup analyses a significantly increased SMR of 231 (Obs 9) was found for those 142 workers with at least five years' employment in the feed handling and nickel extraction departments. In the total cohort there was a single death from nasal cancer (Exp 0.10).

Conclusions: The non-significant excess of lung cancer deaths may well be a chance finding, but in light of previous studies some role for nickel exposures cannot be excluded.
5 ollowing the first report which indicated a possible excess of respiratory cancer in workers from the Mond nickel carbonyl refinery process in Clydach, South Wales, ${ }^{1}$ a number of reports have appeared in the medical literature examining the cancer experience of workers from this refinery. ${ }^{2-6}$ Findings were included in an evaluation of data from 10 cohorts of workers (some 80000 workers involved in nickel mining, smelting, refining, and alloy production) carried out by the International Committee on Nickel Carcinogenesis in Man (ICNCM). ${ }^{7}$ (This evaluation is often referred to as the "Doll Report".) The earlier studies of workers from the Clydach refinery all noted highly significant excesses of respiratory cancers, particularly nasal cancers, occurring in workers employed in the 1920s and 1930s.

A new cohort from the Clydach nickel refinery, more relevant to current processes and working conditions, has now been established. The primary aim of this analysis was to provide information on any lung cancer risks in relation to exposure to four nickel species: metallic, oxide, soluble compounds, and subsulphide.

\section{THE CLYDACH REFINERY PROCESS}

In contrast to the conditions pertaining to the previous studies, ${ }^{1-7}$ the processes operated at Clydach have been improved technically, and occupational dust exposures received by the workforce have been reduced. In addition the range of products produced has been reduced, with the closure of several plants.

The old processes at Clydach have been described previously. ${ }^{7}$ From 1949 onwards, feed to the refinery was limited to oxide materials and the need for sulphur elimination disappeared. In 1958, smelting operations were terminated, coinciding with the change from impure nickel oxide sinter to fluid bed calcine as the feed to the refinery. A reduction in handling steps led to improved work conditions, and the modernisation of the nickel plants that started in 1958 was completed in 1969 with the commissioning of the kiln plants. As a result, the processes operated at Clydach have been improved technically, leading to reduced levels of dust exposure to the workforce. The former categories of nickel plant, central grinding, Orford furnaces, and copper plant ceased to exist; the calciners and hydometallurgical processes were gradually decommissioned and cobalt refining was also modified.

Currently, the nickel oxide calcine feed is reduced with hydrogen and then placed in contact with carbon monoxide to generate nickel carbonyl gas in the kilns. The remaining mixed metal is partially reoxidised and packed automatically into containers for return to the smelter for further processing in Canada. Although the principal product of the refinery remains the spherical metallic pellet, a range of special products has been developed. A wide variety of nickel powders are manufactured for powder metallurgy and for the battery industry. Other materials produced include nickel coated carbon materials both as fibre and graphite powder. High porosity nickel foam has also been produced for the battery industry since 1999. Conversion of a portion of the finished pellet/powder to soluble nickel salts continued to the latter part of the 1990s.

Six categories of work based on the predominant species of nickel exposure are shown in table 1; these classifications of nickel speciation are based on the chemistry of the process tasks rather than on measured occupational speciation exposure data. A comprehensive programme of occupational hygiene dust monitoring has been carried out systematically since 1976, partly to comply with UK and EU regulatory conditions, but principally to support the programme of continuous improvement in control of "nickel in workplace" 
Table 1 Total inhalable nickel dust in air measurements from personal samples $\left(\mathrm{mg} \mathrm{Ni} / \mathrm{m}^{3}\right)$ : Clydach plant

\begin{tabular}{|c|c|c|c|c|c|c|}
\hline \multirow[b]{2}{*}{ Plant } & \multicolumn{2}{|l|}{$1980 \mathrm{~s}$} & \multicolumn{2}{|l|}{$1990 \mathrm{~s}$} & \multirow[b]{2}{*}{ Predominant species* } & \multirow[b]{2}{*}{ Area of plant } \\
\hline & Mean & $\mathbf{n}$ & Mean & $\mathbf{n}$ & & \\
\hline $\mathrm{NiSO}_{4}$ & 0.05 & 30 & 0.04 & 103 & Soluble, metallic & 3 \\
\hline $\mathrm{NiCl}_{2}$ & 0.17 & 122 & 0.30 & 51 & Soluble, metallic & 3 \\
\hline Wet treatment & 0.19 & 202 & $\mathrm{n} / \mathrm{a}$ & - & Metallic, soluble, sulphide & 4 \\
\hline Pellet plant & 0.09 & 222 & 0.07 & 189 & Metallic & 2 \\
\hline Eng. \& tech. services $\ddagger$ & 0.04 & 20 & 0.11 & 169 & Mixed & 6 \\
\hline Powder plant & 0.57 & 403 & 0.37 & 365 & Metallic & 2 \\
\hline Pellet handling§ & 0.13 & 115 & 0.09 & 192 & Metallic & 2 \\
\hline Kiln & 0.19 & 445 & 0.24 & 565 & Oxidic, metallic & $\overline{1}$ \\
\hline Effluent & 0.14 & 28 & 0.19 & 62 & Soluble, metallic & 3 \\
\hline Bulk handling & 0.27 & 3 & 0.12 & 13 & Oxidic, metallic & 1 \\
\hline Fluid bed roaster & 0.49 & 164 & $\mathrm{n} / \mathrm{a}$ & - & Mixed & 1 \\
\hline Calciner & 0.48 & 27 & $\mathrm{n} / \mathrm{a}$ & - & Mixed & 1 \\
\hline \multicolumn{7}{|c|}{$\begin{array}{l}\text { *Little quantitative nickel speciation data are available. } \\
\text { †See text for definition of six categories of work. } \\
\text { †Includes central engineering workshop in the } 1980 \text { s and area } 1 \text { and area } 2 \text { engineering in the } 1990 \mathrm{~s} \text {. } \\
\text { 'Excludes one measurement of } 10.00 \mathrm{mg} / \mathrm{m}^{3} \text {. } \\
\text { §Includes powder warehouse and shipping. }\end{array}$} \\
\hline
\end{tabular}

exposures. Measurements of eight hour TWA total inhalable nickel, based on personal samples collected in the 1980s and 1990s, are summarised in table 1.

\section{METHODS}

The cohort was defined as all male workers $(n=812)$ who were first employed in the factory environment of the Clydach nickel refinery in the period 1953-92 (excludes office staff, canteen staff, laboratory workers, medical staff), and who were so employed for a minimum period of five years (it was not necessary to have five years of continuous employment). The majority of the cohort commenced employment before 1973 (1953-62, $\mathrm{n}=352 ; 1963-72$, $\mathrm{n}=357 ; 1973-82, \mathrm{n}=88 ; 1983-92, \mathrm{n}=15)$.

Detailed work histories at the Clydach site (dates, jobs, and departments) were abstracted from company files in full text form. The median number of job entries per worker was 9 (range 1-22). A department dictionary was developed showing all unique departments described in the work histories $(n=841)$; many entries referred to the same departments described in slightly different ways. Company personnel coded the department dictionary in terms of six categories of work based on the predominant species of nickel exposure: (1) feed handling and nickel extraction, including kilns (oxide/metallic); (2) pellet and powder production, and shipping (metallic); (3) nickel salts and derivatives, and effluent (metallic/soluble); (4) wet treatment and related processes (metallic/subsulphide/soluble); (5) gas plant (non-nickel); and (6) engineering and site wide activities that could include any of the preceding work areas. Smoking status (current smoker, ex-smoker, lifelong nonsmoker) was available in company medical records for 417 subjects (51\% of the cohort).

The vital status of all cohort members on the closing date of the survey (31 December 2000) was established from company personnel files, company pension files, electoral register lists, and returns from the National Health Service Central Register (NHSCR) of the Office for National Statistics (ONS). For those 196 workers who had died, a copy of the death certificate was obtained and the underlying cause of death was coded to the contemporaneous revision of the International Classification of Diseases (ICD); the recorded cause of death was obtained for all deaths. Seven workers had emigrated, and 11 workers were untraced.

Expected numbers of deaths were calculated from male mortality rates for England and Wales (specified by fiveyear age groups and by five-year calendar periods) applied to similarly defined arrays of person-years-at-risk (pyr) generated by the data. Workers entered the pyr at the end of the five years minimum period of employment. They left the pyr on the closing date of the study (31 December 2000), the date of death, or the date of emigration, whichever was the earlier date. These procedures were accomplished by means of the PERSONYEARS software. ${ }^{8}$ No contributions were made to observed or expected numbers past the age of 85 years. This censoring at age 85 was applied for three reasons. Firstly, published mortality rates are only available for the "open ended" age group $\geqslant 85$ and the distribution of the cohort pyr by single years of age might be very different from that of the general population; secondly, the reliability of cause of death particulars is probably poorer at later ages; and thirdly, any study subjects incorrectly classified as traced alive at the end of the study would have a disproportionate effect on the expected numbers for the open ended age group. Subgroup analyses were also calculated for subjects who achieved at least five years cumulative employment in any of the six categories of work described previously.

Overall standardised mortality ratios (SMRs) were calculated as the ratio of observed deaths to expected deaths, expressed as a percentage. The significance of the differences between observed numbers and their corresponding expectations were assessed by means of the Poisson distribution. Confidence intervals were calculated for SMRs based on at least two deaths. Evidence was sought for any trend (linear component) in the pattern of SMRs (for example, any tendency for SMRs to increase or decrease with time since first employment); tests of heterogeneity were also carried out. ${ }^{9}$ Both tests assume a similar null hypothesis; no trend and homogeneous SMRs. Small p values indicate statistical significance, either that the trend is unlikely to have occurred by chance alone or that the amount of heterogeneity is unlikely to have occurred by chance alone. All significance tests were two tailed.

\section{RESULTS}

Observed and expected numbers of death from all causes are shown by year of death and by age at death in table 2 . There was no significant trend or heterogeneity in either set of SMRs. Inadequate tracing of deaths might be indicated by finding low SMRs for overall mortality in the final period of follow up or at later ages; there was a low mortality ratio in the oldest age group (Obs 2, Exp 8.8).

Observed and expected numbers of deaths by broad disease category are shown in table 3. There were no significantly increased SMRs; the SMR for all causes was 96 (Obs 191, Exp 
Table 2 Mortality from all causes in nickel refinery workers $(n=812)$ by year of death and by age at death, 1958-2000

\begin{tabular}{|c|c|c|c|c|}
\hline Variable with levels & Obs & Expt & SMR & $(95 \% \mathrm{Cl})$ \\
\hline \multicolumn{5}{|l|}{ Year of death } \\
\hline $1958-1960$ & 1 & 0.4 & 227 & - \\
\hline $1961-1965$ & 2 & 2.7 & 74 & (9 to 267 ) \\
\hline $1966-1970$ & 4 & 6.3 & 63 & (17 to 162 ) \\
\hline $1971-1975$ & 7 & 12.5 & 56 & (22 to 115 ) \\
\hline $1976-1980$ & 22 & 19.2 & 114 & (72 to 173 ) \\
\hline $1981-1985$ & 22 & 26.7 & 82 & (52 to 125$)$ \\
\hline $1986-1990$ & 31 & 36.1 & 86 & (58 to 122 ) \\
\hline $1991-1995$ & 56 & 44.6 & 126 & (95 to 163 ) \\
\hline 1996-2000 & 46 & 49.7 & 93 & (68 to 123 ) \\
\hline \multicolumn{5}{|l|}{ Age at death } \\
\hline $15-24$ & 0 & 0.8 & 0 & - \\
\hline $25-29$ & 2 & 1.4 & 148 & (18 to 533 ) \\
\hline $30-34$ & 1 & 2.3 & 44 & - \\
\hline $35-39$ & 3 & 4.0 & 76 & (16 to 221 ) \\
\hline $40-44$ & 10 & 7.3 & 138 & (66 to 253 ) \\
\hline $45-49$ & 11 & 13.3 & 83 & (41 to 148 ) \\
\hline $50-54$ & 24 & 20.8 & 115 & (74 to 172 ) \\
\hline $55-59$ & 23 & 27.1 & 85 & (54 to 127 ) \\
\hline $60-64$ & 30 & 31.6 & 95 & (64 to 136) \\
\hline $65-69$ & 35 & 32.8 & 107 & (74 to 149 ) \\
\hline $70-74$ & 26 & 28.9 & 90 & (59 to 132 ) \\
\hline $75-79$ & 24 & 19.5 & 123 & (79 to 183 ) \\
\hline $80-84$ & 2 & 8.8 & $23\left({ }^{*}\right)$ & (3 to 82 ) \\
\hline Total & 191 & 198.3 & 96 & (83 to 111 ) \\
\hline
\end{tabular}

198.3) and the SMR for all neoplasms was 104 (Obs 63, Exp 60.7).

Overall observed and expected numbers of deaths for individual cancer sites (three digit ICD codes) are shown in table 4. There were no significantly increased SMRs; a nonsignificant excess is shown for lung cancer (Obs 28, Exp 20.17) and there was a single death from cancer of the nose and nasal cavities (Exp 0.10). SMRs for all causes and lung cancer were also calculated using local mortality rates (county of West Glamorgan). The SMR for all causes was reduced to 88 (Obs 191, Exp 217.6); the SMR for lung cancer was reduced slightly to 132 (Obs 28, Exp 21.22).

Observed and expected numbers of deaths from lung cancer and from all causes are shown separately by period from commencing employment and by period of commencing employment in table 5. There was no significant trend or heterogeneity in any set of SMRs, although trends by period from hire approached formal levels of statistical significance (lung cancer, $\mathrm{p}=0.07$; all causes, $\mathrm{p}=0.09$ ). The highest SMR for lung cancer was shown for the latest period of follow up ( $\geqslant 30$ y, Obs 16, SMR 186). There were only four deaths (all causes) in those workers first employed in the period 197392.

Observed and expected numbers of deaths from lung cancer and all causes are shown by smoking status in table 6 . The year of stopping smoking was not known for the 80 exsmokers, and for the purpose of this analysis ex-smokers have been combined with smokers. For lung cancer, there were no deaths in non-smokers (Exp 2.1) and there was a highly significant excess in smokers (Obs 16, Exp 6.8, SMR 236). For all causes mortality, significant deficits were shown for non-smokers (Obs 12, Exp 21.5, SMR 56) and for smokers (Obs 45, Exp 67.5, SMR 67); a significant excess was shown for those 395 workers with unknown smoking status (Obs 134, Exp 109.4, SMR 123).

SMRs for lung cancer and for all causes are shown in table 7 for subjects that achieve at least five years cumulative employment in any of six different work categories. There is a

Table 3 Mortality in nickel refinery workers $(n=812), 1958-2000$

\begin{tabular}{|c|c|c|c|c|c|}
\hline Cause of death & ICD9 & Obs & $\operatorname{Exp}^{*}$ & SMR & $(95 \% \mathrm{Cl})$ \\
\hline Infectious and parasitic diseases & $1-139$ & 2 & 1.3 & 156 & (19 to 563 ) \\
\hline Neoplasms & $140-239$ & 63 & 60.7 & 104 & (80 to 133 ) \\
\hline Endocrine nutritional and metabolic diseases & $240-279$ & 1 & 2.6 & 39 & - \\
\hline Diseases of blood & $280-289$ & 1 & 0.5 & 208 & - \\
\hline Mental disorders & $290-319$ & 1 & 1.2 & 86 & - \\
\hline Diseases of nervous system & $320-389$ & 2 & 3.1 & 65 & (18 to 235 ) \\
\hline Diseases of circulatory system & $390-459$ & 85 & 90.5 & 94 & (75 to 116$)$ \\
\hline Diseases of respiratory system & $460-519$ & 18 & 18.6 & 97 & (57 to 153 ) \\
\hline Diseases of digestive system & $520-579$ & 6 & 6.2 & 96 & (35 to 210 ) \\
\hline Diseases of genitourinary system & $580-629$ & 2 & 1.7 & 119 & (14 to 431 ) \\
\hline Diseases of skin & 680-709 & 1 & 0.1 & 881 & - \\
\hline Diseases of musculoskeletal system & $710-739$ & 0 & 0.6 & 0 & - \\
\hline Accidents & $800-949$ & 4 & 6.1 & 66 & (18 to 168 ) \\
\hline Suicide & $950-959$ & 3 & 3.2 & 94 & (19 to 274 ) \\
\hline All causes & & 191 & 198.3 & 96 & (83 to 111 ) \\
\hline
\end{tabular}




\begin{tabular}{|c|c|c|c|c|c|}
\hline Site of cancer & ICD9 & Obs & Exp* & SMR & $(95 \% \mathrm{Cl})$ \\
\hline Lip & 140 & 0 & 0.01 & 0 & - \\
\hline Tongue & 141 & 0 & 0.23 & 0 & - \\
\hline Salivary gland & 142 & 0 & 0.09 & 0 & - \\
\hline Mouth & $143-145$ & 0 & 0.24 & 0 & - \\
\hline Pharynx & $146-149$ & 1 & 0.48 & 208 & - \\
\hline Oesophagus & 150 & 2 & 2.74 & 73 & (9 to 264 ) \\
\hline Stomach & 151 & 7 & 4.25 & 165 & (66 to 339$)$ \\
\hline Small intestine & 152 & 0 & 0.12 & 0 & - \\
\hline Large intestine & 153 & 4 & 4.02 & 99 & (27 to 255$)$ \\
\hline Rectum & 154 & 2 & 2.55 & 78 & (10 to 283 ) \\
\hline Liver & $155.0,155.1$ & 0 & 0.65 & 0 & - \\
\hline Gallbladder & 156 & 0 & 0.24 & 0 & - \\
\hline Pancreas & 157 & 0 & 2.58 & 0 & - \\
\hline Peritoneum & 158 & 0 & 0.12 & 0 & - \\
\hline Other digestive & 159 & 0 & 0.39 & 0 & - \\
\hline Nose and sinuses & 160 & 1 & 0.10 & 995 & - \\
\hline Larynx & 161 & 1 & 0.59 & 169 & - \\
\hline Lung and bronchus & 162 & 28 & 20.17 & 139 & (92 to 201) \\
\hline Pleura & 163 & 1 & 0.39 & 256 & - \\
\hline Bone & 170 & 0 & 0.13 & 0 & - \\
\hline Connective tissue & 171 & 0 & 0.26 & 0 & - \\
\hline Melanoma & 172 & 0 & 0.62 & 0 & - \\
\hline Skin, other & 173 & 0 & 0.15 & 0 & - \\
\hline Breast & 175 & 0 & 0.07 & 0 & - \\
\hline Prostate & 185 & 4 & 3.84 & 104 & (28 to 267$)$ \\
\hline Testis & 186 & 0 & 0.22 & 0 & - \\
\hline Other genital & 187 & 0 & 0.09 & 0 & - \\
\hline Bladder & 188 & 1 & 2.06 & 49 & - \\
\hline Kidney & 189.0 & 3 & 1.39 & 216 & (45 to 632$)$ \\
\hline Other urinary & $189.1-189.9$ & 0 & 0.07 & 0 & - \\
\hline Eye & 190 & 0 & 0.06 & 0 & - \\
\hline Brain & 191-192 & 2 & 1.90 & 105 & (13 to 380$)$ \\
\hline Thyroid & 193 & 0 & 0.10 & 0 & - \\
\hline Other endocrine glands & 194 & 0 & 0.06 & 0 & - \\
\hline Secondary and other cancers & 195-199 & 3 & 4.32 & 69 & (14 to 203 ) \\
\hline Hodgkin's disease & 201 & 0 & 0.38 & 0 & - \\
\hline Lymphosarcoma & 200,202 & 0 & 1.68 & 0 & - \\
\hline Multiple myeloma & 203 & 1 & 0.84 & 116 & - \\
\hline Leukaemia & 204-208 & 1 & 1.56 & 64 & - \\
\hline All neoplasms & $140-239$ & 63 & 60.70 & 104 & (80 to 133$)$ \\
\hline
\end{tabular}

significantly increased SMR for lung cancer in feed handling and nickel extraction workers (Obs 9, Exp 3.9, SMR 231), although there is no significant heterogeneity in either set of
SMRs (lung cancer, $p=0.38$; all causes, $p=0.52$ ) and there is no significant difference between the SMR of 231 and the overall SMR for lung cancer of $139(\mathrm{p}=0.18)$.

\begin{tabular}{|c|c|c|c|c|c|c|}
\hline Cause of death & Variable with levels & Obs & Expt & SMR & $(95 \% \mathrm{Cl})$ & Statistical evaluation \\
\hline $\begin{array}{l}\text { Period from con } \\
\text { Lung cancer }\end{array}$ & $\begin{array}{l}\text { mployment }(y) \\
5-9 \\
10-19 \\
20-29 \\
\geqslant 30 \\
\text { Total }\end{array}$ & $\begin{array}{r}1 \\
1 \\
10 \\
16 \\
28\end{array}$ & $\begin{array}{r}0.8 \\
3.6 \\
7.2 \\
8.6 \\
20.2\end{array}$ & $\begin{array}{r}133 \\
28 \\
138 \\
186^{*} \\
139\end{array}$ & $\begin{array}{l}- \\
- \\
(66 \text { to } 254) \\
(106 \text { to } 301) \\
(92 \text { to } 201)\end{array}$ & $\begin{array}{l}\text { het., } p=0.21 \\
\text { trend, } p=0.07\end{array}$ \\
\hline All causes & $\begin{array}{l}5-9 \\
10-19 \\
20-29 \\
\geqslant 30 \\
\text { Total }\end{array}$ & $\begin{array}{r}5 \\
27 \\
70 \\
89 \\
191\end{array}$ & $\begin{array}{r}10.1 \\
35.3 \\
65.3 \\
87.6 \\
198.3\end{array}$ & $\begin{array}{r}49 \\
77 \\
107 \\
102 \\
96\end{array}$ & $\begin{array}{l}(16 \text { to } 115) \\
(50 \text { to } 111) \\
(84 \text { to } 135) \\
(83 \text { to } 111) \\
(83 \text { to } 111 \text { ) }\end{array}$ & $\begin{array}{l}\text { het., } p=0.19 \\
\text { trend, } p=0.09\end{array}$ \\
\hline $\begin{array}{l}\text { Year of commer } \\
\text { Lung cancer }\end{array}$ & $\begin{array}{l}\text { yment } \\
1953-62 \\
1963-72 \\
1973-92\end{array}$ & $\begin{array}{r}18 \\
10 \\
0\end{array}$ & $\begin{array}{r}13.2 \\
6.4 \\
0.6\end{array}$ & $\begin{array}{r}137 \\
156 \\
0\end{array}$ & $\begin{array}{l}(81 \text { to } 216) \\
\text { (75 to } 286) \\
-\end{array}$ & $\begin{array}{l}\text { het., } p=0.62 \\
\text { trend, } p=0.84\end{array}$ \\
\hline All causes & $\begin{array}{l}1953-62 \\
1963-72 \\
1973-92\end{array}$ & $\begin{array}{r}123 \\
64 \\
4\end{array}$ & $\begin{array}{r}126.8 \\
64.1 \\
7.5\end{array}$ & $\begin{array}{r}97 \\
100 \\
53\end{array}$ & $\begin{array}{l}(81 \text { to } 116) \\
(77 \text { to } 128) \\
(15 \text { to } 137)\end{array}$ & $\begin{array}{l}\text { het., } p=0.47 \\
\text { trend, } p=0.60\end{array}$ \\
\hline
\end{tabular}

${ }^{*} \mathrm{p}<0.05$.

†Based on mortality rates for England and Wales. 
Table 6 Mortality from lung cancer and from all causes in relation to smoking status, 1958-2000

\begin{tabular}{|c|c|c|c|c|}
\hline Smoking status & Obs & Expt & SMR & $(95 \% \mathrm{Cl})$ \\
\hline \multicolumn{5}{|l|}{ Lung cancer } \\
\hline Non-smoker $(n=139)$ & 0 & 2.1 & 0 & - \\
\hline Smoker $¥(n=278)$ & 16 & 6.8 & 236 ** & (135 to 383 ) \\
\hline$n / k(n=395)$ & 12 & 11.3 & 106 & (55 to 185$)$ \\
\hline \multicolumn{5}{|l|}{ All causes } \\
\hline Non-smoker $(n=139)$ & 12 & 21.5 & $56\left(^{*}\right)$ & (29 to 98 ) \\
\hline Smoker $¥(n=278)$ & 45 & 67.5 & $67\left(^{* *}\right)$ & (49 to 89 ) \\
\hline$n / k(n=395)$ & 134 & 109.4 & $123^{*}$ & (103 to 145 ) \\
\hline
\end{tabular}

\section{DISCUSSION}

Occupational exposures are unlikely to have discernible effects on the risks of mortality from all causes combined. Consequently, patterns of mortality from all causes are more likely to be due to selection effects, socioeconomic gradients, regional effects, or lifestyle effects than they are to occupational exposures. In this study, there was evidence of a healthy worker effect, with mortality rates being well below the national average in the early periods of follow up (population selected for health at entry to the industry) and with the magnitude of this deficit reducing with time (regression towards the mean). It is important to gauge the size of this effect, because this sort of pattern (SMRs increasing with period from hire) is the same pattern we might expect to see with occupational cancers.

Analyses of mortality risks from lung cancer in relation to job category found a significantly increased SMR for long term workers $(\geqslant 5 y)$ in feed handling and nickel extraction, although given that a number of significance tests were carried out it is not that unusual that one test provided a significant outcome. There is an overlap with membership of the current cohort and the Clydach cohort analysed in the ICNCM report; ${ }^{7}$ eight of the nine deceased workers involved in the above excess were also members of the earlier cohort (first employed in the period 1902-64). A job-exposure matrix for all periods of interest is not currently available and, consequently, analyses in relation to cumulative nickel exposure have not been attempted. Such analyses would, however, assist with the interpretation of these data by taking into account improvements in working practices and dust extraction that have been introduced over the years.
The overall absolute difference in observed and expected deaths for lung cancer is only eight deaths. It is very difficult to establish the presence of an occupation risk factor, even if one were present, based on such a small absolute excess. The nonsignificant excess of lung cancer deaths may well be a chance finding, but in light of both the significant excess of lung cancer for long term follow up and the previous studies on earlier entrants to the industry, ${ }^{1-7}$ a further follow up incorporating a job exposure matrix is recommended to investigate possible occupational influences more thoroughly. While further follow up will increase statistical power, the modest size of the cohort will limit the potential for reliable interpretation. Consequently, pooling this study with other more recent cohorts of nickel exposed workers may offer a more informative way forward. There was only a single death from nasal cancer in the cohort in the period under study; it follows that no form of statistical analysis could usefully be carried out for this disease. The current findings for lung and nasal cancers are in marked contrast to the clear excesses shown for workers from this refinery hired before $1930 .{ }^{1-7}$ Further follow up should allow examination of the post- ICNCM sub-cohort that may well have benefited from the significant process changes that have been introduced to reduce exposure levels.

\section{ACKNOWLEDGEMENTS}

We thank the Office for National Statistics (ONS) for assisting with the collection of follow up information. We thank Senior Nurse Helena Thomas for abstraction of work and smoking histories, and Eric Collinson for process descriptions and advice on industrial hygiene matters. We thank Margaret Williams for word processing. The costs of this analysis were defrayed by a research award from Inco Europe Limited.

Table 7 Mortality from lung cancer and from all causes in workers who have achieved five years cumulative employment in specified job categories

\begin{tabular}{|c|c|c|c|c|c|}
\hline Job category† & n & Obs & Exp‡ & SMR & $(95 \% \mathrm{Cl})$ \\
\hline \multicolumn{6}{|l|}{ Lung cancer } \\
\hline Feed handling and nickel extraction & 142 & 9 & 3.9 & $231^{*}$ & (106 to 439$)$ \\
\hline Pellet and powder production & 219 & 9 & 5.3 & 171 & (78 to 325$)$ \\
\hline Nickel salts and derivatives & 121 & 6 & 2.7 & 219 & (80 to 477 ) \\
\hline Wet treatment and related processes & 166 & 7 & 5.6 & 125 & (50 to 257 ) \\
\hline Gas plant & 47 & 1 & 1.2 & 84 & - \\
\hline Engineering and site wide activities & 343 & 7 & 7.8 & 90 & $(36$ to 186$)$ \\
\hline \multicolumn{6}{|l|}{ All causes } \\
\hline Feed handling and nickel extraction & 142 & 32 & 37.6 & 85 & (58 to 120$)$ \\
\hline Pellet and powder production & 219 & 40 & 51.2 & 78 & (56 to 106$)$ \\
\hline Nickel salts and derivatives & 121 & 28 & 26.5 & 106 & (70 to 153 ) \\
\hline Wet treatment and related processes & 166 & 59 & 53.7 & 110 & (84 to 142 ) \\
\hline Gas plant & 47 & 9 & 11.3 & 80 & (36 to 151$)$ \\
\hline Engineering and site wide activities & 343 & 66 & 77.1 & 86 & (66 to 109$)$ \\
\hline
\end{tabular}

${ }^{*} \mathrm{p}<0.05$.

†Subjects can contribute person-years-at-risk and observed deaths to more than one category.

$\ddagger$ Based on mortality rates for England and Wales. 
Authors' affiliations

T Sorahan, Institute of Occupational and Environmental Medicine, University of Birmingham, Edgbaston, Birmingham, UK

S P Williams, INCO Europe Ltd, Clydach Refinery, Swansea, UK

\section{REFERENCES}

1 Morgan JG. Some observations on the incidence of respiratory cancer in nickel workers. Br J Ind Med 1958;15:224-34.

2 Doll R, Morgan LG, Speizer FE. Cancers of the lung and nose in nickel workers. Br J Cancer 1970;24:623-32.

3 Doll R, Mathews JD, Morgan LG. Cancers of the lung and nasal sinuses in nickel workers: a reassessment of the period of risk. $\mathrm{Br} J$ Ind Med 1977;34:102-5.

4 Peto J, Cuckle H, Doll R, et al. Respiratory cancer mortality of Welsh nickel refinery workers. In: Sunderman FW Jr, ed. Nickel in the human environment.
IARC sci pub no.53. Lyon: International Agency for Research on Cancer, 1984:37-46.

5 Kaldor J, Peto J, Easton D, et al. Models for respiratory cancer in nickel refinery workers. J Natl Cancer Inst 1986;77:841-8.

6 Easton DF, Peto J, Morgan LG, et al. Respiratory cancer mortality in Welsh nickel refiners: which nickel compounds are responsible. In: Nieboer $E$, Nriagu JO, eds. Nickel and human health: current perspectives. New York: John Wiley \& Sons, 1992.

7 ICNCM Report. Report of the International Committee on Nickel Carcinogenesis in Man. Scand J Work Environ Health 1990;16:1-82.

8 Coleman M, Douglas A, Hermon C, et al. Cohort study analysis with a Fortran computer program. Int J Epidemiol 1986;15:134-7.

9 Breslow NE, Day NE. Statistical methods in cancer research. Vol II. The design and analysis of cohort studies, IARC sci pub no 82. Lyon: International Agency for Research on Cancer, 1987.

\section{$\mathrm{ECHO}$}

\section{Psychological and social factors precede work disability in RA}

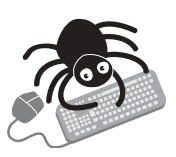

Please visit the Occupational and

Environmental Medicine website [www. occenvmed. com] for a link to the full text of this article. systematic review may have unearthed clues to interventions that might prevent work disability in rheumatoid arthritis (RA), a common problem for those with the disease. It found strong evidence for limitations on activity-high HAQ disability-and physically demanding work predicting work disability on the basis of best evidence synthesis, confirming previous results. Surprisingly, evidence for biomedical variables predicting work disability was inconsistent. The researchers suggest that work disability arises from a biopsychosocial mismatch between work and the worker and that directed interventions might reduce it. However, much greater understanding is needed of employability, lifestyle, physical work tasks, and coping styles and of predictors of work disability in early versus late disease. Given that HAQ disability embodies structural damage, disease activity, pain, and psychological factors, interventions will need to include treatment of the disease and associated problems too.

The review included only studies in which predictive factors preceded work disability and excluded studies examining drug treatment, though the researchers concede that medical treatment in early RA may prevent work disability. They point out that predictors were determined as having a statistical, not an aetiological, link and may be conservative.

Thirteen studies were reviewed. Only 19 papers met the initial criteria out of 391 citations obtained from a search of Cinahl, Embase, and Medline databases (1988/9-2004).

Work disability in RA is generally supposed to result from reduced function versus job demands, but most research has focused on predictive factors in the context of rehabilitation, not prevention.

A De Croon EM, et al. Annals of the Rheumatic Diseases 2004;63:1362-1367. 